03

\title{
Структура электрогидродинамических течений инжекционного типа в переменном поле
}

\author{
(C) А.А. Коротков, Ю.К. Стишков \\ Санкт-Петербургский государственный университет, \\ 199034 Санкт-Петербург, Россия \\ I e-mail: y.stishkov@gmail.com
}

Поступило в Редакцию 28 ноября 2019 г.

В окончательной редакции 28 ноября 2019 г.

Принято к публикации 5 фревраля 2020 г.

Приведены результаты исследования структуры электрогидродинамических (ЭГД) течений в переменном электрическом поле. Исследование проведено на основе результатов компьютерного моделирования ЭГДтечений в системе электродов игла-плоскость. Рассмотрен характерный диапазон частот питающего синусоидального напряжения амплитудой $5 \mathrm{kV}$. Проведено описание изменения зарядовой и скоростной структур ЭГД-течений, выявлены характерные особенности в зависимости от частоты изменения питающего напряжения. Показана периодичность данного вида ЭГД-течений.

Ключевые слова: электрогидродинамическое течение, ЭГД-течение, переменное электрическое поле, зарядовая структура, скоростная структура.

DOI: $10.21883 /$ JTF.2020.08.49535.383-19

\section{Введение}

Электрогидродинамические (ЭГД) течения в жидких диэлектриках впервые описаны Фарадеем, и всесторонне исследованы экспериментально еще в прошлом столетии, и описаны в фундаментальных работах [14]. Следующий шаг в исследованиях произошел с появлением возможности решать сложную, нелинейную систему ЭГД-уравнений с помощью численных расчетов с использованием ЭВМ [5-6]. Обобщение результатов современных исследований ЭГД-течений, возникающих при воздействии постоянного напряжения в различных системах электродов, приведено в монографии [7].

Исследования ЭГД-течений посвящены в основном описанию структуры этих течений при воздействии постоянным напряжением. Настоящая работа посвящена изучению ЭГД-течений инжекционного типа в переменном электрическом поле в характерном диапазоне частот. Исследование проведено методом численного моделирования базовой системы уравнений электрогидродинамики для сильно неоднородного электрического поля в системе электродов игла-плоскость. Для этой системы уже имеется обширная информация по исследованию ЭГД-процессов при постоянном напряжении [7], также данная модель является характерной для лабораторных систем, что позволит сопоставить полученные результаты с экспериментом. Малый радиус закругления игольчатого электрода позволяет создать сильно неоднородное поле с локальной напряженностью много больше среднего значения. Это позволяет осуществить инжекцию при сравнительно малых значениях напряжения между электродами, а также решать задачу в условиях униполярной инжекции.

\section{Описание модели}

Система уравнений электрогидродинамики, описывающая ЭГД-процессы в несжимаемых жидких диэлектриках, состоит из уравнения Нернста-Планка для положительных и отрицательных ионов (1),(2), закона Гаусса в дифференциальной форме (3), уравнения связи напряженности электрического поля с потенциалом (4), уравнения Навье-Стокса (5), уравнения неразрывности среды (6) и уравнения для определения суммарной плотности заряда (7):

$$
\begin{gathered}
\frac{\partial n_{+}}{\partial t}+\operatorname{div}\left(-D \nabla n_{+}+Z_{+} b n_{+} \mathbf{E}+n_{+} \mathbf{u}\right)=W_{0}-\alpha_{r} n_{+} n_{-} \\
\frac{\partial n_{-}}{\partial t}+\operatorname{div}\left(-D \nabla n_{-}+Z_{-} b n_{-} \mathbf{E}+n_{-} \mathbf{u}\right)=W_{0}-\alpha_{r} n_{+} n_{-} \\
\operatorname{div}(\mathbf{E})=\frac{\rho}{\varepsilon \varepsilon_{0}} \\
\mathbf{E}=-\nabla \varphi \\
\gamma \frac{\partial \mathbf{u}}{\partial t}+\gamma(\mathbf{u}, \nabla) \mathbf{u}=-\nabla P+\eta \Delta \mathbf{u}+\rho \mathbf{E} \\
\operatorname{div}(\mathbf{u})=0 \\
\rho=Z_{+} n_{+} e+Z_{-} n_{-} e .
\end{gathered}
$$

Здесь $n_{+}, n_{-}$- концентрация положительных и отрицательных ионов, $D$ - коэффициент диффузии, $Z_{+}, Z_{-}-$ зарядовое число положительных и отрицательных ионов, $t$ - время, $e-$ элементарный заряд, $b-$ подвижность ионов, и - скорость жидкости, $W_{0}$ - интенсивность диссоциации, $\alpha_{r}$ - коэффициент рекомбинации, $\mathbf{E}-$ 


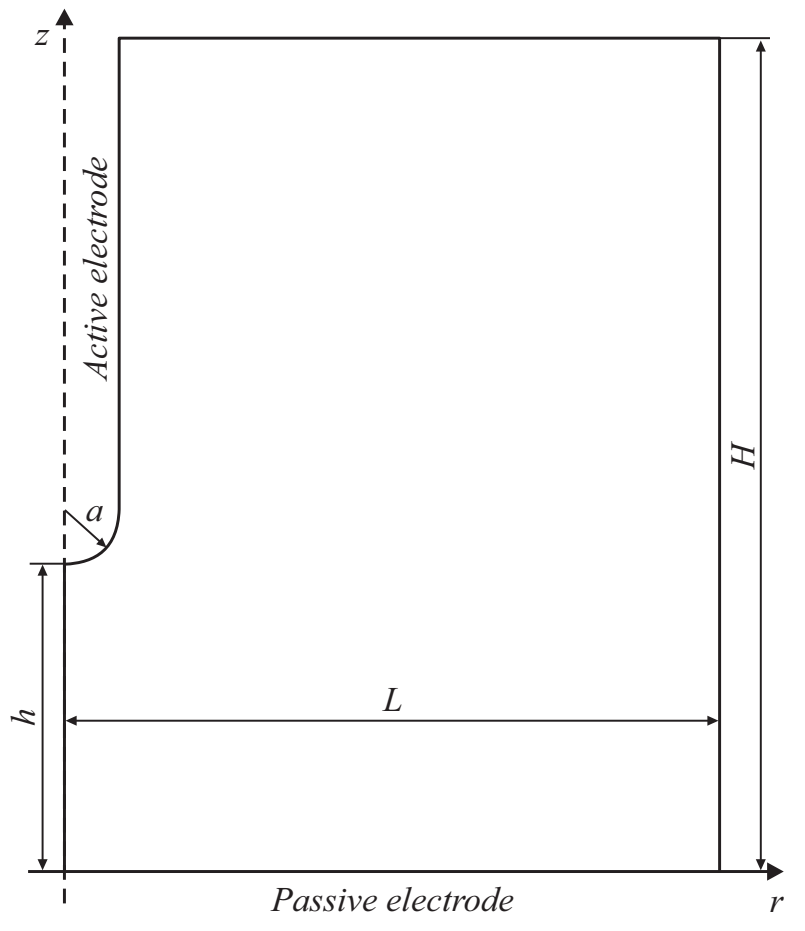

Рис. 1. Геометрия модели.

напряженность электрического поля, $\varepsilon, \varepsilon_{0}-$ диэлектрические проницаемости жидкости и вакуума, $\rho$ - объемная плотность заряда, $\varphi$ - потенциал электрического поля, $\gamma-$ механическая плотность жидкости, $\eta-$ динамическая вязкость жидкости, $P$ - давление. В настоящей работе используются одновалентные отрицательные и положительные ионы: $Z_{+}=1, Z_{-}=-1$, которые обладают одинаковыми подвижностью, интенсивностью диссоциации и коэффициентом рекомбинации.

Исследуемая система представляет собой цилиндрическую кювету, в которую помещена игла - активный электрод, пассивным электродом является дно кюветы. Для расчетов была реализована двумерная осесимметричная конечноэлементная модель. Высота кюветы $H=20 \mathrm{~mm}$, радиус кюветы $L=15 \mathrm{~mm}$, длина межэлектродного промежутка (МЭП) $h=7 \mathrm{~mm}$. Радиус иглы и радиус закругления острия $a=0.1 \mathrm{~mm}$ (рис. 1).

Рассматривается зарядообразование инжекционного и диссоционного типа с учетом рекомбинации. Инжекция происходит с поверхности активного электрода (иглы) и зависит от полярности. Так, при положительной полярности с поверхности электрода инжектируются положительные ионы, а при отрицательной - отрицательные. В объеме положительные и отрицательные ионы рекомбинируют с ионами противоположного знака независимо от способа образования последних.

Коэффициент рекомбинации вычисляется по формуле Ланжевена, который с учетом $\left|Z_{-}\right|=\left|Z_{+}\right|=1$ принимает вид: $a_{r}=2 b e / \varepsilon \varepsilon_{0}$. Коэффициент диффузии определяется соотношением Эйнштейна: $D=b k_{B} T / e$, где $k_{B}-$ постоянная Больцмана, $T$ - температура.
Низковольтная удельная проводимость вещества $\sigma$ в отсутствие электрического поля определяет равновесную концентрацию ионов $n_{e q}$ и связана с ней выражением $n_{e} q=\sigma / 2 b e$. Полученная таким образом равновесная концентрация задавалась в качестве начальных условий для концентраций положительных и отрицательных ионов.

Интенсивность диссоциации определяется из соображения равенства интенсивности диссоциации и рекомбинации в отсутствие электрического поля $W_{0}-\alpha_{r} n_{e q}^{2}=0$.

Гибель ионов также происходит на поверхности электродов противоположной полярности и задается соответствующим условием $j_{v}=j_{b}$, которое означает моментальную нейтрализацию ионов, здесь $j_{v}-$ поток ионов из объема, $j_{b}$ - поток через границу.

Граничные условия задачи дополняются равенством нулю скорости течения на любых твердых поверхностях. На боковой и верхней диэлектрических стенках нормальная компонента электрического поля равна нулю, это задается условием $\mathbf{n} \cdot E=0$, где $\mathbf{n}-$ вектор нормали к поверхности, так же на эти поверхности задается непроникновение ионов $-j \cdot \mathbf{n}=0$. Нижний плоский электрод заземлен $V=0$. На верхний активный электрод задается потенциал, изменяющийся по гармоническому закону (8):

$$
V=V_{0} \cos (2 \pi \nu t)
$$

где $V_{0}=5 \mathrm{kV}$ - амплитуда, $v$ - частота питающего напряжения, которая варьировалась в ходе исследования в характерном диапазоне $v=0.125-8 \mathrm{~Hz}$. Характерный диапазон частот выбирался на основе безразмерного параметра (9):

$$
R=T /(2 \tau)
$$

равного отношению полупериода питающего напряжения $T$, к времени $\tau$ пересечения заряженной струей ЭГД-течения МЭП. Последнее выбиралось по данным, приведенным в монографии [7], и равно $\tau \approx 0.3 \mathrm{~s}$. Границы характерного диапазона частот соответствуют значениям безразмерного параметра $R=13.3$ (для $v=0.125 \mathrm{~Hz}$ ) и $R=0.2$ (для $v=8 \mathrm{~Hz}$ ), и позволяют предсказать особенности ЭГД-течения при воздействии переменным напряжением: при частотах выше $v=8 \mathrm{~Hz}$ ЭГД-течение не должно возникать, а при частотах ниже $v=0.125 \mathrm{~Hz}$ структура ЭГД-течения ожидается близкой к структуре при постоянном напряжении.

Как уже отмечалось, инжекция в сильно неоднородном поле происходит только с электрода-иглы. Она задается в виде функциональной зависимости от локальной напряженности электрического поля (10):

$$
j(E)=A\left(E-E_{s t}\right) \theta\left(E-E_{s t}\right) .
$$

Здесь $A=1 \cdot 10^{9}(\mathrm{~V} \cdot \mathrm{m} \cdot \mathrm{s})^{-1}, E_{s t}=5 \cdot 10^{6} \mathrm{~V} / \mathrm{m}$ - константы, $E$ - модуль напряженности электрического поля, $\theta(E)$ - функция Хевисайда. Как видим, инжекция ионов имеет пороговый характер, линейно зависит от локальной напряженности вблизи поверхности электрода и является симметричной для двух сортов ионов. 

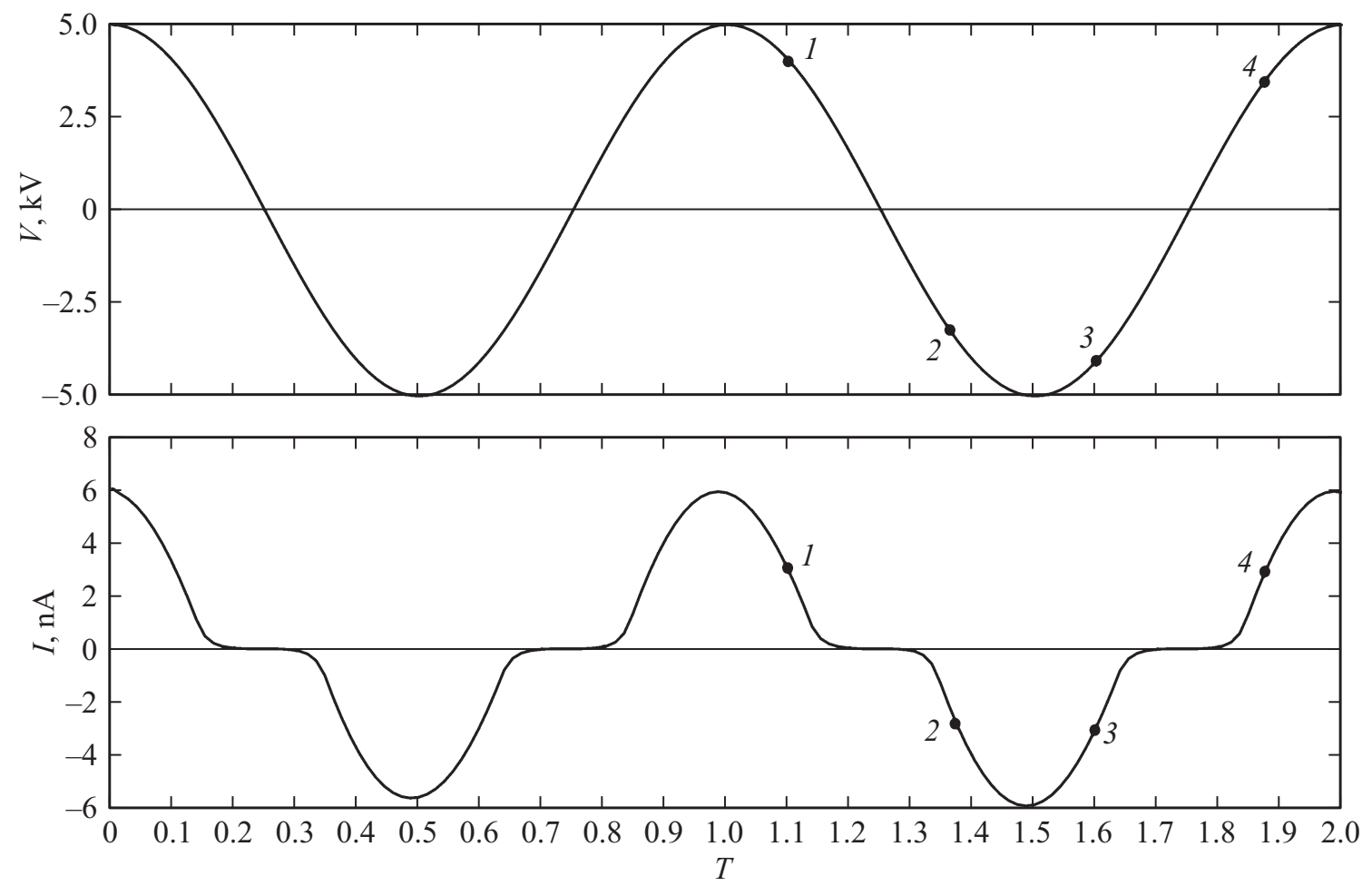

Рис. 2. Осциллограмма напряжения и тока инжекции в зависимости от частей периода. Точками отмечены характерные моменты.

Физические свойства среды соответствуют трансформаторному маслу: механическая плотность $\gamma=850 \mathrm{~kg} / \mathrm{m}^{3}$, относительная диэлектрическая проницаемость $\varepsilon=2.2$, динамическая вязкость $\eta=0.02 \mathrm{~Pa} \cdot \mathrm{s}$, низковольтная удельная проводимость $\sigma=1 \cdot 10^{-11} \mathrm{~S} / \mathrm{m}$, подвижность ионов $b=1 \cdot 10^{-8} \mathrm{~m}^{2} /(\mathrm{V} \cdot \mathrm{s})$. Температура жидкости оставалось постоянной $T=293.15 \mathrm{~K}$.

\section{Анализ результатов моделирования}

Перейдем к рассмотрению результатов, полученных при помощи компьютерного моделирования методом конечных элементов в программном комплексе COMSOL Multiphysics, приведенных на рис. 2-6.

Время установления ЭГД-течения при включении постоянного напряжения величиной $5 \mathrm{kV}$ в трансформаторном масле составляет $\tau \approx 0.3 \mathrm{~s}$ [7]. Распределение кулоновской силы в режиме установившегося ЭГД-течения неизменно и определяет типовую зарядовую и скоростную структуры ЭГД-течения: от электрода-иглы к плоскому электроду распространяется тонкая струйка объемного заряда, испытывающая действия кулоновских сил. У острия игольчатого электрода находится короткая зона ускорения, далее следует зона квазиоднородного течения и зона торможения у плоского электрода.

При воздействии переменного напряжения данная картина меняется. В течение первого полупериода картина аналогична течению при включении постоянного напряжения: от игольчатого электрода в незаряженную жидкость распространяется тонкая струйка инжектированного заряда. Однако после смены полярности напряжения с активного электрода начинает инжектироваться заряд противоположного знака. Направление действия кулоновской силы на этот заряд остается прежним, поэтому от игольчатого электрода к плоскому распространяется струйка основного ЭГД-течения. Однако вместе с тем в дальней части межэлектродного промежутка присутствует область остаточного заряда противоположного знака, не успевшая покинуть межэлектродный промежуток, которая испытывает действие встречной кулоновской силы. Она создает локальное встреченное ЭГД-течение. Так как поле имеет резко неоднородный характер, то интенсивность встречного ЭГД-течения значительно ниже основного. Описанная картина существенно зависит от времени и длительности периода питающего напряжения. Рассмотрим картину более подробно.

Вместе с переменным напряжением ток инжекции также обладает периодичностью, однако благодаря пороговому характеру зависимость тока инжекции от времени имеет несколько иной характер. На рис. 2 представлены осциллограммы напряжения и тока инжекции. По ним видно, что ток инжекции не равен нулю в течение четверти периода в положительном и отрицательном полупериоде напряжения. Можно отметить также, что ток инжекции несколько отстает по фазе от питающего напряжения, это отставание не превышает $2.5 \%$ от периода. 

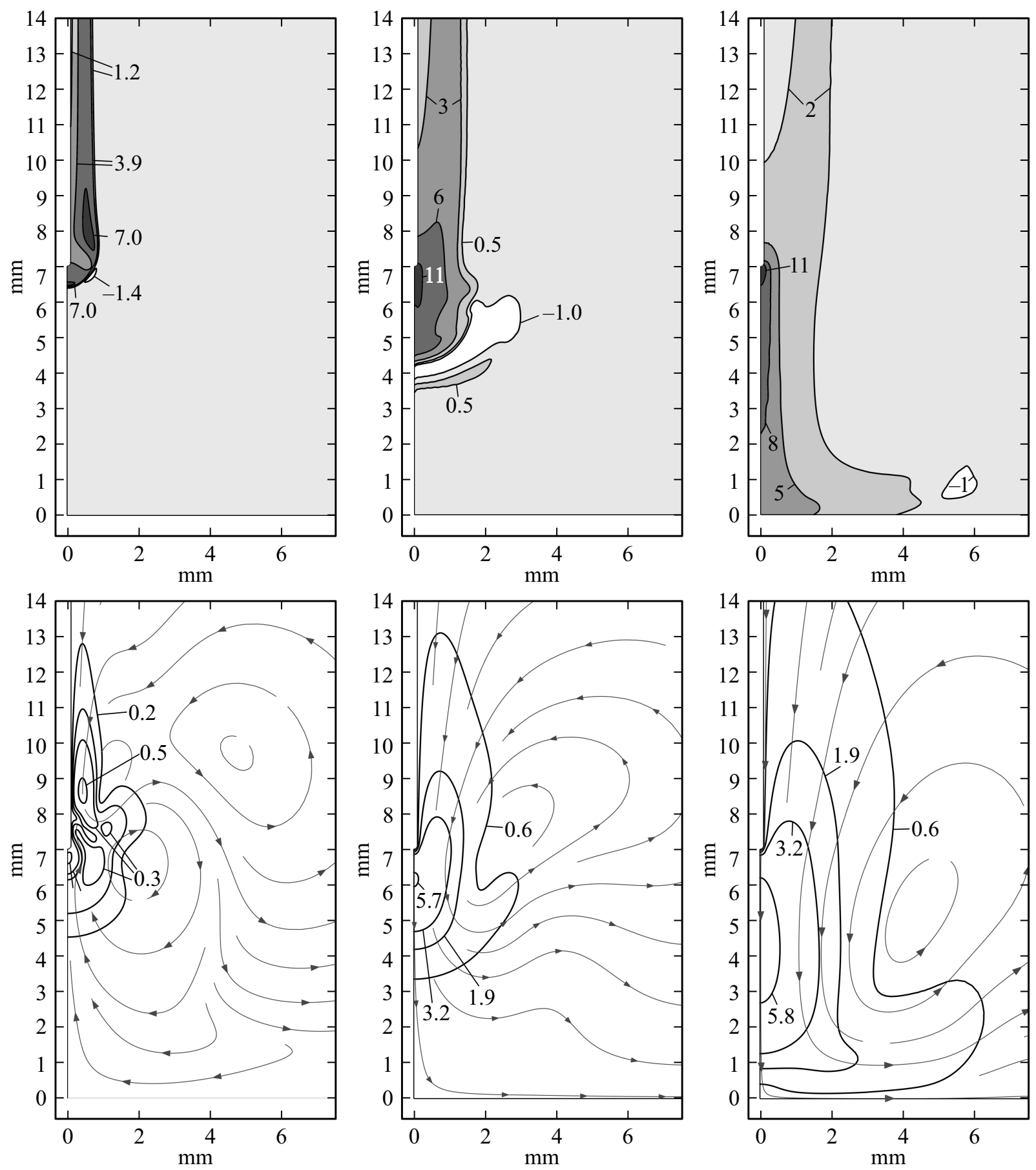

Рис. 3. Распределение зарядовой структуры (вверху) и поля скоростей с линиями тока (внизу) в момент времени $1.1 T$ для частот $v=8,2,0.5 \mathrm{~Hz}$. Единицы измерения объемной плотности заряда $\left[\mathrm{mC} / \mathrm{m}^{3}\right]$, скорости $[\mathrm{cm} / \mathrm{s}]$.

Сила Кулона, действующая на основной инжектирующийся заряд, также носит периодический характер. Однако она не меняет направление и всегда действует от игольчатого электрода к плоскому, формируя основное ЭГД-течение. Можно определить характерный диапазон частот переменного напряжения, в котором ЭГД-процессы наиболее интересны. Если полупериод питающего напряжения много больше времени пересечения центральной струей межэлектродного промежутка, то остаточ- ный заряд выносится к противоэлектроду, и встречное течение практически не возникает. Поэтому структура основного ЭГД-течения должна близко соответствовать структуре течения при постоянном напряжении. Это соответствует значениям безразмерного параметра $R \gg 1$. При $R \ll 1$ заряженная струйка инжектированного с игольчатого электрода заряда не успеет сформироваться и поэтому ЭГД-течения возникать не должны. Структура и интенсивность возникающего ЭГД-течения зависит от 

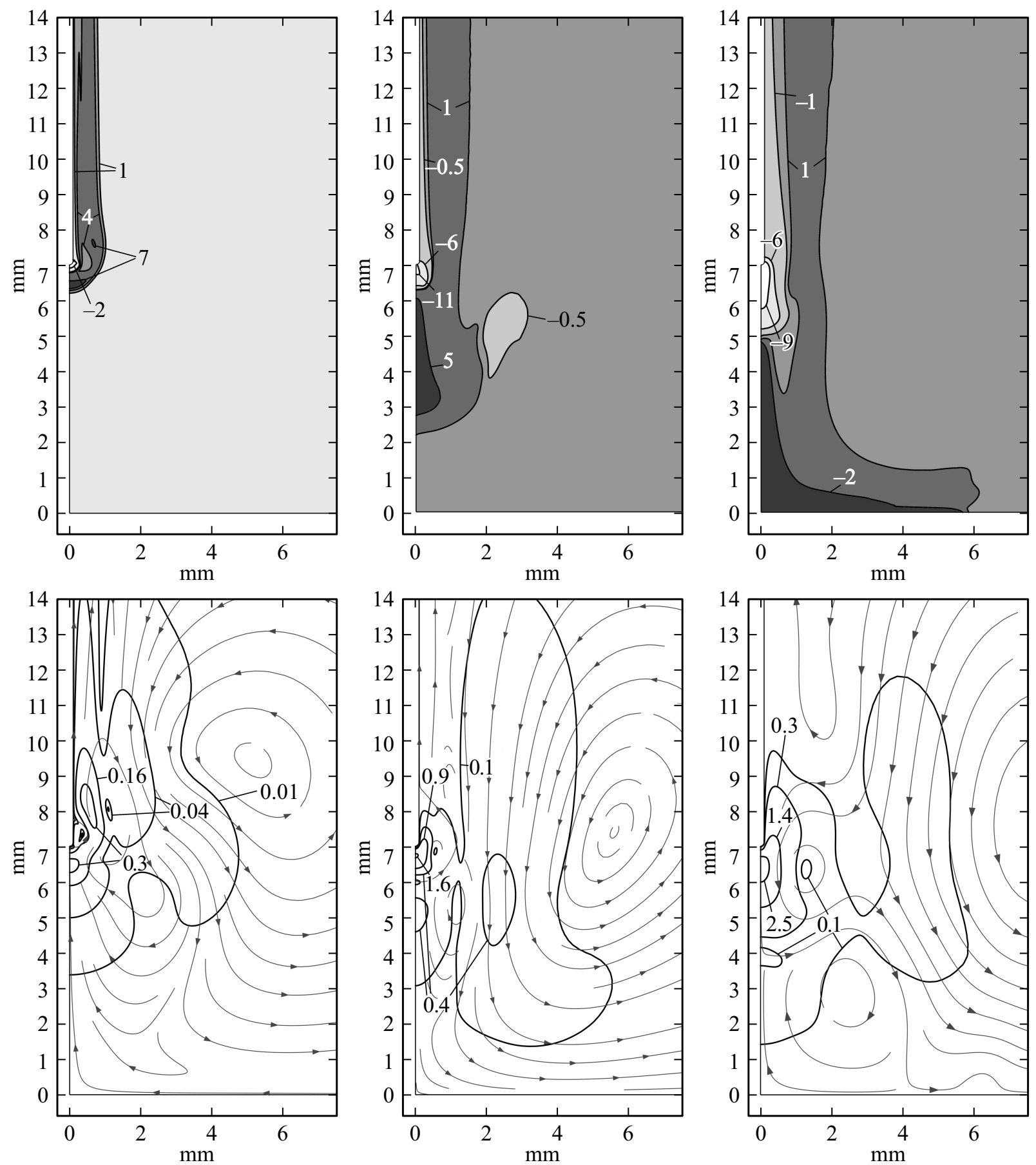

Рис. 4. Распределение зарядовой структуры (вверху) и поля скоростей с линиями тока (внизу) в момент времени $1.35 T$ для частот $v=8,2,0.5 \mathrm{~Hz}$. Единицы измерения объемной плотности заряда $\left[\mathrm{mC} / \mathrm{m}^{3}\right]$, скорости $[\mathrm{cm} / \mathrm{s}]$.

времени. Для описания характерной текущей структуры необходимо выбрать моменты времени, в которых будет проведен анализ.

Первый полупериод выделяется тем, что инжекция происходит в электронейтральную жидкость. В следующие полупериоды влияние остаточного заряда на структуру ЭГД-течения значительно. Для нахождения закономерностей рассмотрим структуру ЭГД-течения в моменты времени, соответствующие $1.1 T, 1.35 T, 1.6 T$,
$1.85 T$ после включения переменного напряжения с частотой $0.5,2$ и $8 \mathrm{~Hz}(R=3.3,0.8,0.2$ соответственно). В указанные моменты времени ток инжекции равен половине от максимального значения, однако в моменты $1.35 T$ и 1.85 Т полуволна текущего тока инжекции растет, а в моменты $1.1 T$ и $1.6 T$ спадает. Отметим также, что частоты 8 и $0.5 \mathrm{~Hz}$ отражают два квазикритических случая: на высокой частоте $8 \mathrm{~Hz}$ заряженная струйка за полупериод напряжения не успевает сформи- 

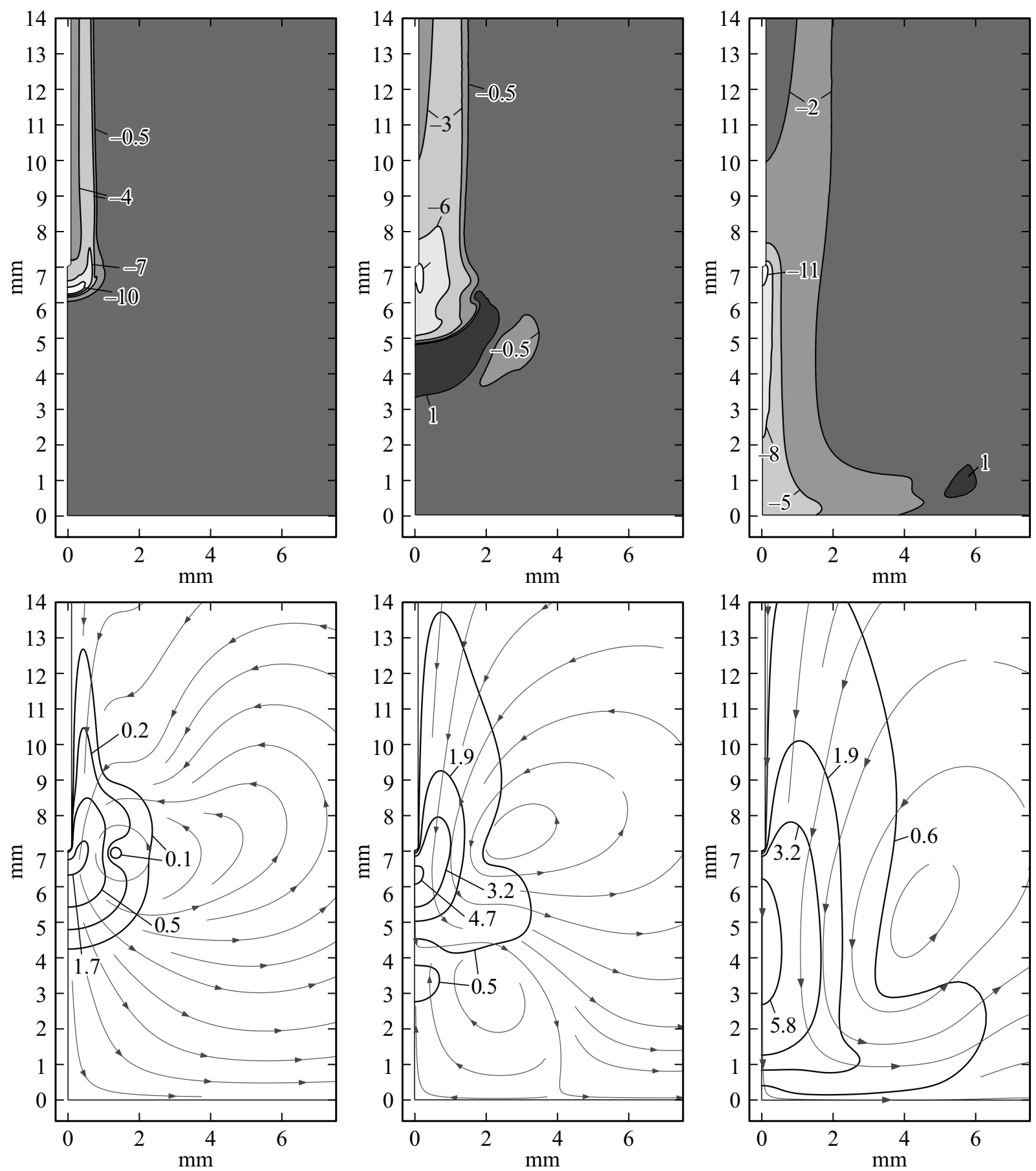

Рис. 5. Распределение зарядовой структуры (вверху) и поля скоростей с линиями тока (внизу) в момент времени $1.6 T$ для частот $v=8,2,0.5 \mathrm{~Hz}$. Единицы измерения объемной плотности заряда $\left[\mathrm{mC} / \mathrm{m}^{3}\right]$, скорости $[\mathrm{cm} / \mathrm{s}]$.

роваться, на низкой частоте за полупериод напряжения заряженная струйка успевает пересечь межэлектродный промежуток. На рис. 3-6 приведены результаты моделирования: зарядовые структуры (вверху) и поля скоростей с линиями тока жидкости (внизу) в различные моменты времени.

В момент 1.1T происходит инжекция положительного заряда с игольчатого электрода (рис. 3). Чем меньше частота, тем глубже заряженная струйка успевает про- никнуть в межэлектродный промежуток. Видно, что при частоте $8 \mathrm{~Hz}$ заряженная струя не успевает сформироваться, а приэлектродный заряженный слой имеет толщину всего $0.1 h$, и слабое ЭГД-течение локализовано в окрестности поверхности иглы и направлено на игольчатый электрод. При частоте $2 \mathrm{~Hz}$ длина заряженной струи составляет $0.4 \mathrm{~h}$ и ЭГД-течение направлено от игольчатого электрода и занимает половину МЭП, а при частоте питающего напряжения $0.5 \mathrm{~Hz}$ ЭГД-течение направлено 

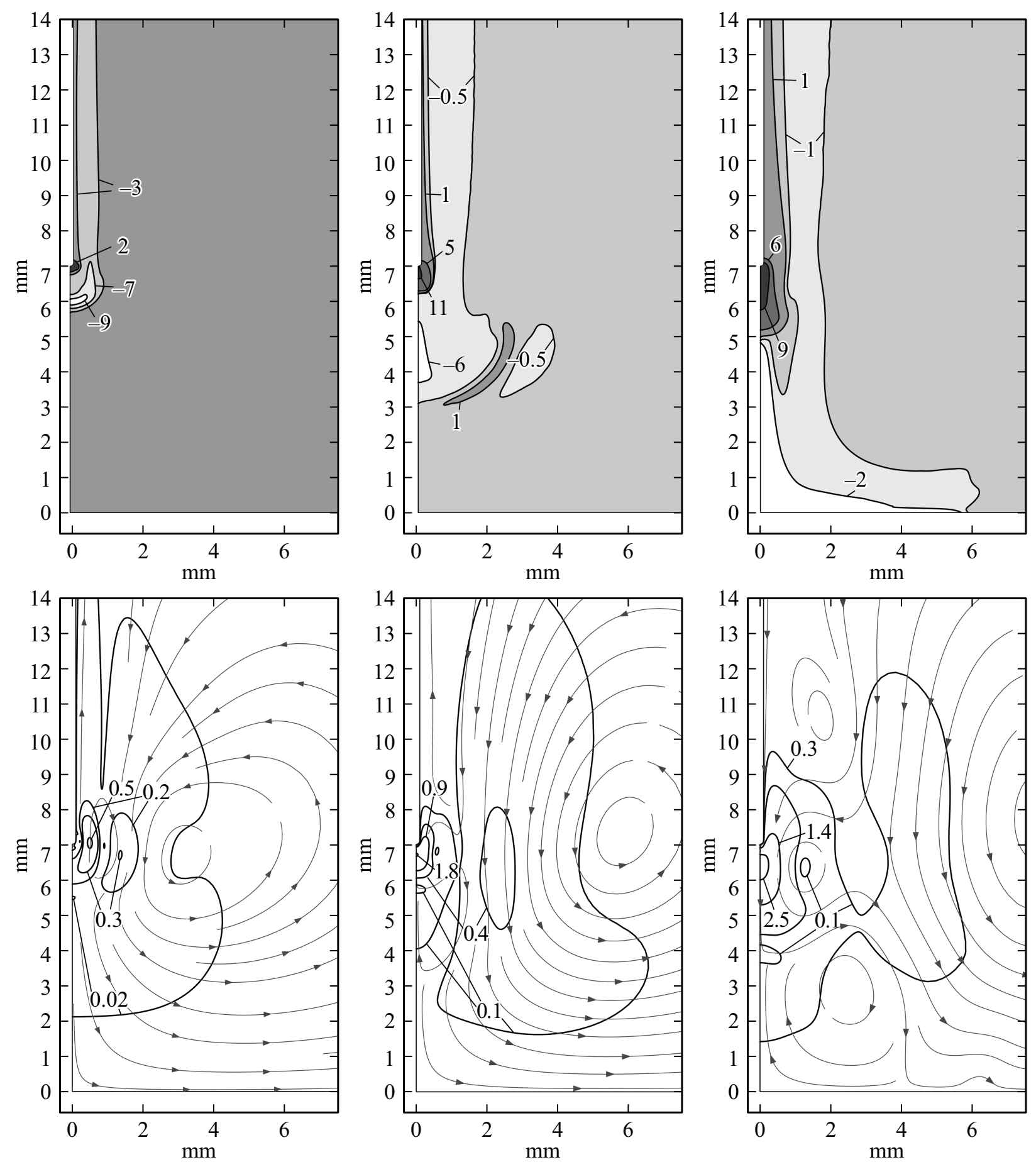

Рис. 6. Распределение зарядовой структуры (вверху) и поля скоростей с линиями тока (внизу) в момент времени $1.85 T$ для частот $v=8,2,0.5 \mathrm{~Hz}$. Единицы измерения объемной плотности заряда $\left[\mathrm{mC} / \mathrm{m}^{3}\right]$, скорости $[\mathrm{cm} / \mathrm{s}]$.

от игольчатого электрода к плоскому, заряженная струйка достигает противоположного электрода и растекается по его поверхности. При этом структура ЭГД-течения максимально похожа на случай воздействия постоянного напряжения, т.е. имеется короткая зона ускорения, зона квазиоднородного течения, занимающая большую часть межэлектродного промежутка, и зона торможения у противоэлектрода [7].
В фазе отрицательной полуволны напряжения (рис. 4) с активного электрода начинает инжектироваться отрицательный заряд. Сила Кулона, действующая на поступающий с игольчатого электрода заряд, как и ранее, направлена от игольчатого электрода и формирует основную струйку ЭГД-течения, направленную к плоскому электроду. Однако в середине межэлектродного промежутка присутствует положительный заряд, оставшийся 

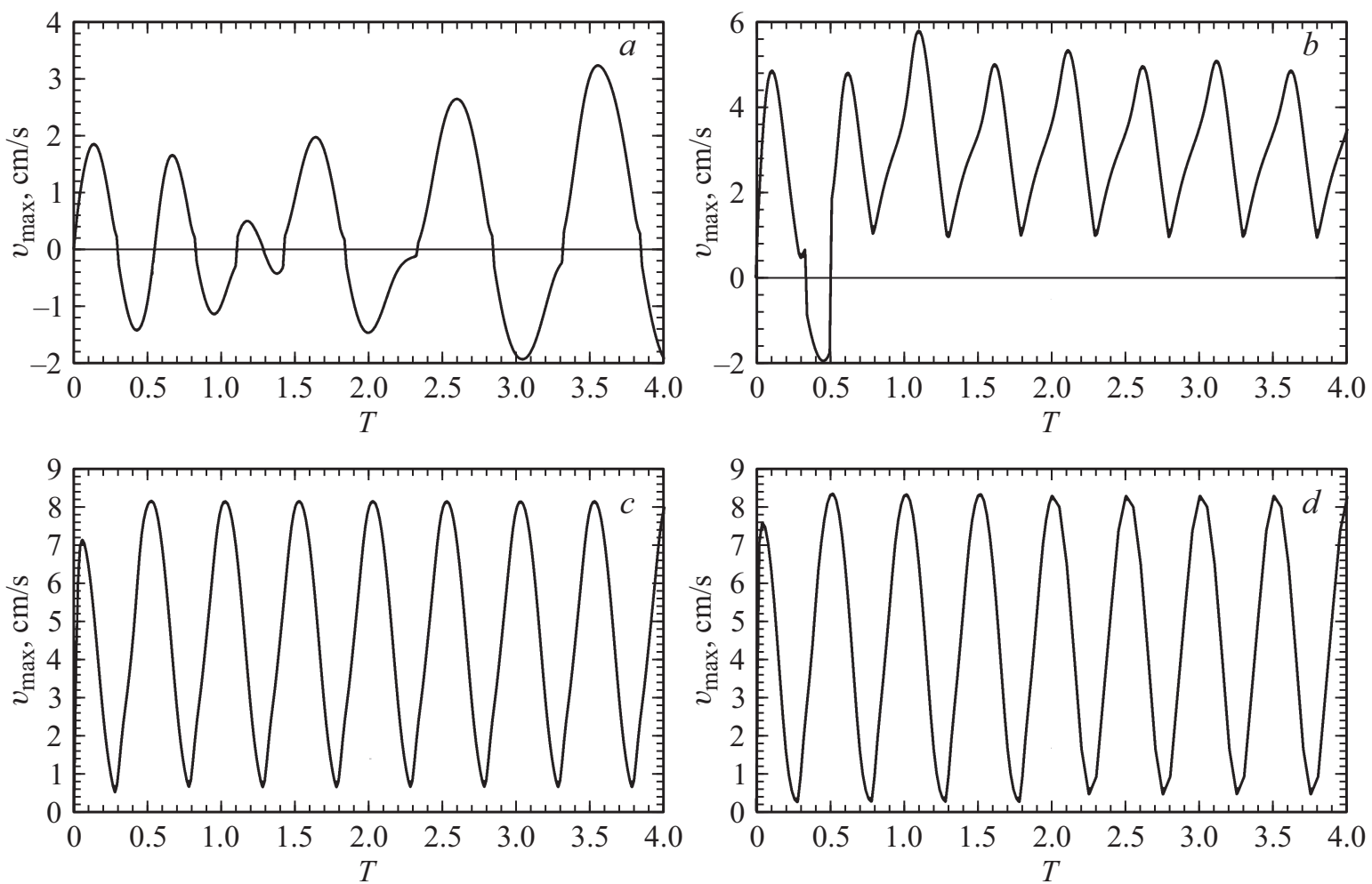

Рис. 7. Зависимость максимальной скорости ЭГД-течения от времени при различных частотах питающего напряжения: $a-8$, $b-2, c-0.5, d-0.25 \mathrm{~Hz}$.

с прошлого полупериода, на который сила Кулона действует в обратном направлении. На рис. 4 приведены распределения зарядовой структуры и поля скоростей в момент времени 1.35T. К этому моменту струйка отрицательного заряда еще не успела глубоко проникнуть в межэлектродный промежуток, и скоростная структура носит сложный, многоячеистый характер (рис. 4): отрицательно заряженная струйка движется к плоскому электроду, а остаточная положительная область назад к игольчатому электроду. В результате противоположно заряженные части создают два встречных вихря, причем на границах потоков происходит рекомбинация ионов разных знаков.

На рис. 5 представлено распределение объемного заряда и скоростной структуры в момент 1.6T. При достаточно малых частотах питающего напряжения главная отрицательная струя успевает снести остатки противозаряда к плоскому электроду в область пониженной напряженности поля, где действие встречных сил существенно ослаблено и к моменту 1.6T формируется хорошо выраженное основное ЭГД-течение. От длительности полупериода зависит глубина проникновения отрицательной струйки и интенсивность результирующего ЭГД-течения. Наибольшая максимальная скорость наблюдается при частоте $0.5 \mathrm{~Hz}$, эта скорость близка к значению максимальной скорости в аналогичной системе, но с постоянным напряжением. Наименьшая скорость ЭГД-течения наблюдается при частоте $8 \mathrm{~Hz}$, при этом слабое ЭГД-течение локализовано у острия игольчатого электрода и направлено от игольчатого электрода к плоскому.

В начале следующей полуволны напряжения от игольчатого электрода вновь распространяется струйка положительного заряда, длина которой растет с ростом параметра $R$. К моменту $1.85 T$ инжектирующийся заряд еще не проник в глубину межэлектродного промежутка (рис. 6). Роль остаточного противозаряда в этот момент времени играет отрицательный заряд. Он занимает обширную область и на него действует сила Кулона, направленная на электрод-иглу. Формируется многовихревая ЭГД-структура, которая похожа на аналогичный случай для отрицательной полуволны питающего напряжения в момент $1.35 T$ (ср. рис. 6 и 4).

Далее картина течения повторяется. Таким образом, при инжекции, зависящей от полярности напряжения, текущие структуры ЭГД-течений, возникающих при воздействии положительной и отрицательной полуволны напряжения, идентичны и зависят от безразмерного параметра $R$. Поэтому изменение модуля максимальной скорости ЭГД-течений в этих условиях происходит с удвоенной частотой. На рис. 7 приведена зависимость максимальной скорости ЭГД-течения от времени при различных частотах питающего напряжения: $0.25,0.5,2$ и $8 \mathrm{~Hz}$. За положительное направление скорости взято направление в сторону плоского электрода. 
Поскольку при высоких частотах питающего напряжения, когда глубина проникновения заряженной стройки значительно меньше длины МЭП, зависимость максимальной скорости от времени носит знакопеременный характер, что связано с биполярной структурой струи. $\mathrm{C}$ уменьшением частоты питающего напряжения, a следовательно, с увеличением глубины проникновения заряженной струйки за полупериод напряжения, максимальная скорость течения перестает изменять знак, однако зависимость максимальной скорости течения от времени по-прежнему носит периодический характер, причем частота изменения скорости удвоена по отношению к частоте питающего напряжения (рис. 7). Дальнейшее уменьшение частоты питающего напряжения от 0.5 до $0.25 \mathrm{~Hz}$ не вносит существенных изменений в структуру возникающих ЭГД-течений, она остается подобной структуре ЭГД-течения в постоянном поле. Увеличение частоты питающего напряжения выше $8 \mathrm{~Hz}$ приводит к полному исчезновению направленных ЭГДтечений, поскольку за полупериод не успевает сформироваться центральная заряженная струйка, а при более высоких частотах и заряженный слой вокруг игольчатого электрода.

\section{Заключение}

• Проведено моделирование ЭГД-течений инжекционного типа при воздействии переменного электрического поля в характерном диапазоне частот, определяемом безразмерным параметром $R$, равным отношению половине периода питающего напряжения к характерному времени ЭГД-течений. Показано, что особенности скоростной структуры ЭГД-течений при воздействии переменным напряжением обусловлены остаточным объемным зарядом.

- В результате анализа временной структуры результатов моделирования установлено, что изменение знака объемного заряда центральной струи ЭГД-течения происходит периодически с периодом, равным полупериоду изменения напряжения.

- При малых значениях $R \ll 1$ заряженная струйка не успевает сформироваться и направленные ЭГД-течения от инжектирующего электрода практически не возникают, при $R \sim 1$ продольная структура центральной струи носит знакопеременный характер, а при значениях $R \gg 1$ наблюдается униполярно заряженная струйка, пересекающая межэлектродный промежуток.

- Выявлен периодический характер изменения скоростной структуры ЭГД-течения с частотой, равной удвоенной частоте питающего напряжения. При $R \sim 1$ в течение первой и третьей четверти периода наблюдается преимущественно униполярная струйка жидкости, а в течении второй и четвертой четверти наблюдаются встречные противоположно заряженные струйки, формирующие четырехячеистые структуры. При $R \gg 1$ пространственная скоростная структура ЭГД-течений в переменном поле идентична структуре ЭГД-течений в постоянном поле.

- Показано, что средняя скорость основной струйки ЭГД-течения изменяется пропорционально удвоенной частоте питающего напряжения.

\section{Благодарность}

Компьютерное моделирование проведено с использованием вычислительных ресурсов „Вычислительного центра СПбГУ“ (http://cc.spbu.ru).

\section{Конфликт интересов}

Авторы заявляют, что у них нет конфликта интересов.

\section{Список литературы}

[1] Остроумов Г.А. Взаимодействие электрических и гидродинамических полей. М.: Наука, 1979. 320 с.

[2] Стишков Ю.К., Остапенко А.А. Электрогидродинамические течения в жидких диэлектриках. Л.: Изд-во ЛГУ, 1989. $176 \mathrm{c}$.

[3] Castellanos A., Perez A. Electrohydrodynamic systems. In: Springer Handbook of Experimental Fluid Dynamics / Eds. C. Tropea, A. Yarin, J. Foss. Berlin: Springer-Verlag, 2007. P. $1317-1333$.

[4] Жакин А.И.Э // УФН. 2012. Т. 182. № 5. С. 495-520.

[5] Стишков Ю.К., Чирков В.А. // ЖТФ. 2008. Т. 78. Вып. 11. C. 11-16. [Stichkov Yu.K., Chirkov V.A. // Tech. Phys. 2008. Vol. 53. N 11. P. 1407-1413.] DOI: $10.1134 / \mathrm{S} 1063784208110030$

[6] Стишков Ю.К., Чирков В.А. // ЖТФ. 2012. Т. 82. Вып. 1. C. $3-13$.

[7] Стишков Ю.К. Электрофизические процессы в жидкостях при воздействии сильных электрических полей. М.: Юстицинформ, 2019. $262 \mathrm{c}$. 